\title{
Use of Artificial Intelligence in Smart Cities for Smart Decision-Making: A Social Innovation Perspective
}

\author{
Syed Asad A. Bokhari ${ }^{1}$ (D) and Seunghwan Myeong ${ }^{2, *(D)}$ \\ 1 Center of Security Convergence \& eGovernance, Inha University, Incheon 22212, Korea; \\ asad.bokhari@inha.edu \\ 2 Department of Public Administration, Inha University, Incheon 22212, Korea \\ * Correspondence: shmyeong@inha.ac.kr
}

check for updates

Citation: Bokhari, S.A.A.; Myeong, S. Use of Artificial Intelligence in Smart Cities for Smart Decision-Making: A Social Innovation Perspective. Sustainability 2022, 14, 620. https:// doi.org/10.3390/su14020620

Academic Editors: Marwa Mahmoud and Maria Perez-Ortiz

Received: 26 November 2021

Accepted: 4 January 2022

Published: 6 January 2022

Publisher's Note: MDPI stays neutral with regard to jurisdictional claims in published maps and institutional affiliations.

Copyright: (C) 2022 by the authors. Licensee MDPI, Basel, Switzerland. This article is an open access article distributed under the terms and conditions of the Creative Commons Attribution (CC BY) license (https:// creativecommons.org/licenses/by/ $4.0 /)$.

\begin{abstract}
The goal of this study is to investigate the direct and indirect relationships that exist between artificial intelligence (AI), social innovation (SI), and smart decision-making (SDM). This study used a survey design and collected cross-sectional data from South Korea and Pakistan using survey questionnaires. Four hundred sixty respondents from the public and private sectors were obtained and empirically analyzed using SPSS multiple regression. The study discovered a strong and positive mediating effect of SI between the relationship of AI and SDM, as predicted. Previous researchers have investigated some of the factors that influence the decision-making process. This study adds to the social science literature by examining the impact of a mediating factor on decision-making. The findings of this study will contribute to the local government in building smart cities such that the factor of social innovations should be involved in the decision-making process because smart decision-making would share such collected data with entrepreneurs, businesses, and industries and would benefit society and all relevant stakeholders, including such social innovators.
\end{abstract}

Keywords: smart cities; artificial intelligence; social innovation; smart decision-making; mediating role

\section{Introduction}

The use of artificial intelligence (AI) in smart cities, its effect on governance, decisionmaking, innovative discipline, and prospects of revolution have been a topic of discussion in debate and practice recent years [1-6]. Data generation utilizing AI is possible in government and private sectors exploring new approaches to understand our world. The availability of big data may be effective in optimum usage of resources while making informed decisions [7]. Artificial intelligence and the Internet of Things [8,9] can positively influence smart decision-making [10]. At present, AI is becoming a need for daily life and organizational procedures as technology has taken great dives in empowering AI advancement [11]. AI contributes to smart cities' decision-making because smart decisionmaking utilizes a systematic and organized approach to collect data and applies rational decision-making systems rather than using hit and miss, instinct, or generalizing from overall experience [12].

"Smart cities" is a multidimensional notion and has been defined differently by numerous scholars. However, the compulsory prerequisite to being a smart city is to attain sustainable social, environmental, and economic development and improve the living standards of society by utilizing Information and Communication Technology (ICT) and AI [13]. The technological aspect of a smart city in the decision-making process can be defined as "a technologically interconnected city" or the use of artificial intelligence with big data to accomplish the intelligence and efficiency in managing the city's resources [14]. A study about smart decision-making in smart cities using big data [12] introduced a three-layer framework characterizing a smart city as an "instrumented, interconnected, and intelligence". Smart cities in the implemented phase utilize artificial intelligence and 
IoT for data acquisition by using surveillance cameras, meters, and sensor-based systems for real-time data and from open data sources and social media for quick response. The data collected through AI, IoT, and other sources are integrated and then transformed into a piece of relative information in the "interconnected" phase to deliver better insights for smart decision-making. Finally, transformed information gathered through data is envisioned to understand the city's demands, requirements, needs, and policies. Hence, it can contribute to well-informed and smart decision-making [15,16].

The role of artificial intelligence in the SDM process has long been discussed and acknowledged by many smart city scholars [17-20]. However, different factors can impact decision-making in smart cities. Several scholars [21,22] have recently highlighted that decision-making in smart cities is not affected by ICT only. However, the city managers should listen to the people and stakeholders of the society and include them in this process. Evidently, [23] found how digital towns may be utilized to embed planning and decisionmaking and design codes into the city's e-governance. Moreover, [24] suggested several measures available to improve the energy efficiency of smart cities, and city managers must compensate for energy, environmental, social, and financial factors to make smart decisions. Although it is found that AI has a positive impact on smart decision-making in smart cities, we believe that other important factors mediate between these two variables.

Despite the extensive research outline explained above, our knowledge of the exact use of AI on the SDM process in smart cities is still limited and inconsistent in many ways. For instance, [25] argued that transparency should be seen both in designing AI assistants and the decision-making process, ensuring more legitimacy in the public eye rather than in the process. The advancement of $\mathrm{AI}$ in the form of learning algorithms is beneficial in expanding our comprehension of how the elevated smart city operates, but it is challenging to see how such approaches could ever dominate decision-making in the near future [2]. What anticipated is that $\mathrm{AI}$ will inform the SDM process in the same manner that various computer instruments serve as the foundation of planning support systems. Moreover, [4] identified the challenges linked with the impact of artificial intelligence-based systems on smart decision-making. They proposed a set of suggestions for IS scholars and discussed the integration of AI support to replace humans in decision-making in particular. Jarrahi [26] provided a more pragmatic and proactive perspective by highlighting the complementarity of humans and AI by examining how the strength of each one can be utilized in the decisionmaking process in organizations characterized by complexity, uncertainty, and equivocality. Hence, the involvement of humans is important, and AI assistance can be utilized as a part of the decision-making process. Another significant weakness, we believe, is the lack of a foundational theoretical framework linking $\mathrm{AI}$ and the smart decision-making process via the mediating role of social innovation (the design and implementation of new solutions).

In their study, [27] proposed a research framework to simplify the interaction between technology and social innovation to develop timely, pre-emptive, and sustainable plans and strategies for decision-making. They have figured out how to use economic incentives to benefit society while also protecting the environment. Gibson-Graham and Roelvink [28] also highlighted a framework about social innovation, explaining that it is concerned with relegated social groups and their involvement in social decision-making. Drawing on these frameworks, we propose that the relationship between artificial intelligence and smart decision-making is indirect, rather than direct, mediated through social innovation.

This research aims to see how artificial intelligence, with the help of social innovation, influences decision-making in smart cities. To the best of our knowledge, we uncovered this gap in existing work, and we believe that our research will contribute to the literature on artificial intelligence and smart cities. This research will help academics and government officials better understand the need for social innovation and how it influences the interaction between artificial intelligence and smart decision-making in smart governance systems.

The remainder of the research is structured as follows: The literature review and hypothesis building are explained in Section 2 after the introduction in Section 1. Section 3 describes the research methodology, data gathering, and data analysis. Tables, figures, and 
diagrams are used in Section 4 to present the findings. Finally, in Section 5, concluding remarks, limitations, and research directions are discussed.

\section{Literature Review and Hypothesis}

\subsection{Artificial Intelligence}

Although artificial intelligence has received minimal attention in the public sector, there is an increased tendency in concentration, as seen by an increase in AI studies and technical reports [3,29-32]. In these studies, the benefits of artificial intelligence applications in the public sector have been highlighted across numerous government departments, showing that AI's vast potential is impeded by technical, organizational, and policy challenges [29].

Previously, researchers have demonstrated the critical role of artificial intelligence in the rational decision-making processes, making a city smart and encouraging a high quality of life in practice. Scholl and AlAwadhi [30] highlighted how AI-enabled governance enables cities to collaborate to create smart services that no single city can provide. Smart governance in smart cities encourages data collection from sensors and other sources to improve urban safety governance [33]. For example, the South Korean government recently used artificial intelligence to combat the COVID-19 epidemic by encouraging proactive information exchange, assisting citizens in understanding the issue, and implementing recently released safety protocols [34].

Artificial intelligence (AI) in smart cities has become a critical aspect of cities facing massive challenges such as confirming social presence, sustainability, public health and safety, prosperity, and making smart decisions [35,36]. When cities face such encounters, they implement a variety of concepts to transmute their cities into smart cities. This progression contains a variety of AI strategies that are generally endorsed by urban politicians who create the governing systems, as well as other experts all over the world [35]. Although several ICT tools, such as databases and dashboards, can help decision-making, artificial intelligence stands out because of its three design characteristics. However, the most important feature is automated learning and decision-making procedures through advanced mathematical representations of problems [32].

In their study, [25] created a framework to analyze transparency in AI decision-making in the socio-technological system, and they asserted that a confined type of transparency in the shape of justifications for decisions-both regarding the design of AI assistants and the decisions taken by them-has the potential to ensure more legitimacy in the eyes of the public than transparency in process. When it comes to apparent legitimacy, we must greatly prefer that our AI assistants justify themselves rather than opening their code, etc. for public feedback. The same holds true for decision-makers' decisions during the process of setting goals and pertinent factors for the assistants.

By overwhelming common mistakes in administrative decision-making, artificial intelligence provides a method for improving power structure in government. These common problems include inappropriate forecasts on important administrative tasks such as awarding a small business loan, unrestricted bias such policing unreliable citation rates, and decision quality varying due to differences in accuracy between managers or over time owing to decision exhaustion [4,37]. AI can help solve such problems by being more consistent with diminishing variance and prejudice, more accurate, more lucrative by reducing labor costs associated with repetitive tasks, and less corruptible by founding a stronger link between data inputs and decisions [32].

\subsection{Artificial Intelligence in Smart Cities and Decision-Making}

Artificial intelligence (AI) has proven useful in decision-making in various fields, including smart cities, medical tests and diagnostics, organizations, the public and private sector, and medicine. Previous research, for instance, found that AI can reliably identify diseases as precisely, and especially in ophthalmology [38], complex treatment decisions may be handled better by AI modeling than by intuition alone, and there is potential to 
expand this framework as a technical infrastructure for personalized medicine [39]. The application of contemporary AI techniques to forecast high-impact weather is expanding our capability to scrutinize massive numbers of data in order to extract perceptions and correct, appropriate guidance for human weather analysts and decision-makers [40], in complex tasks. AI with exceptional quantitative, computational, and analytical abilities has outstripped humans with algorithmic decision-making. When combined, big data in organizations [26] and the advancement of AI in the method of machine learning will be beneficial in expanding our perception of how the high-frequency, real-time city operates, but it is hard to see how such approaches could ever influence decision-making in the very near future [2].

Smart cities are highly complexly built, with extremely sophisticated integrated technologies that contain a substantial number of sensors and equipment linked to computerized systems that include analytics, surveillance, and decision-making algorithms [41] and use of Internet of Things in smart cities [42]. The notion of a "smart city" is difficult to explain due of its complexities. Numerous scholars' attempts to provide a relevant and complete definition center on individuals or communities, or on their living standards [43]. Only a few mention the role of public and private organizations in promoting standard of living, while others focus on the ecological impact of urbanization activities and use of information communication infrastructure [44,45]. We, in our study, focus on the definition by Caragliu [46], which explains that a city is considered smart when investments are made social, and human capital and conventional and information communication technology infrastructure support long-term economic development and a better quality of life while managing natural resources efficiently via participatory governance.

$\mathrm{AI}$ informs the decision-making process in the same manner that various computer technologies serve as the foundation of planning support systems. In terms of smart city planning, few tools have been produced to demonstrate how AI may advance the state of the art. Years ago, it dabbled with expert systems. However, they fell out of favor as overly simplistic and apparent, despite some of the capabilities that resulted from these innovations [47]. Numerous researchers emphasized that processing and interpreting big data collected via $\mathrm{AI}$ is a vital step towards enriching the decision-making in smart cities $[1,12,18]$. As cities are becoming smart and digitized globally by installing sensors, computer cores, and other communication networks [48], as pushed by the modern notion of "Smart", this is becoming increasingly possible [1]. These digital ideas are linked to AI and machine learning technologies, which enable collecting near real-time data, allowing for a better knowledge of how cities change, adapt, and respond to diverse environments. Allam and Dhunny [1] agreed that big data analysis might help urban city governors for smart decision-making and help cities assist socio-economic factors while assuring the execution of policies. Hence, we develop the following hypothesis:

Hypothesis 1. Artificial intelligence, by using big data, has a positive influence on smart decisionmaking in smart cities.

\subsection{Artificial Intelligence, Social Innovation, and Smart Decision-Making}

As a significant dimension, this variable emphasizes "collaboration" between government, community, and other stakeholders that contribute to the decision-making process in smart cities. Megacities require a strong managerial structure to facilitate collaboration between the society and government to make better policy and smart decision-making for integrated administration $[49,50]$. It necessitates integrating internal governance structures and establishing partnerships with external organizations [51]. A study about the determinants of factors that contribute to smart city development [6] concluded that public-private partnership is one of the five factors that make a city smarter. They explained that citizens' or residents' participation in urban policy decisions is not merely as beneficiaries simply; rather, they contribute to the overall decision-making process and the government. Local 
governments in smart cities involve their communities, private organizations, and other social actors to make better policies and decision-making beneficial for everyone.

To improve cities' social, economic, and ecological performance, this style of collective smart governance aims to build "innovation hubs" [52] by fostering constructive links between networks of actors, information centers, and resource institutions. The Amsterdam Smart City illustrates collaborative urban governance by displaying a unique relationship between municipal administration, private businesses, research institutes, start-up investors, entrepreneurs, innovators, ordinary citizens, and other relative stakeholders [53,54]. With the assistance from the extended cooperation of more than 2207 people and organizations, Amsterdam city, being smart, developed numerous projects spanning six areas that include infrastructure and technology involving energy, water, waste management, transportation, the living standard of citizens, and education [55]. Governors of this city brand it as an "urban living lab", inviting usage of collected data through artificial intelligence to entrepreneurs from private and public sources to create apps and test pilot creative ideas for bettering businesses and services. Engaging inhabitants and communities through the "Smart Citizen" program, which recruits people to participate as data agents, is vital for developing a smart city [56]. Amsterdam residents operate as data collection agents, exhibiting their knowledge on sustainability issues and directly connecting with their city, assisting in the city's advancement as a smart city.

Social innovation denotes "penetration of business ideas, management practices, and market principles into the world of non-profits and government" [57]. Artificial intelligence has a great potential to impact the way social actors engage themselves and interact with their government for decision-making. Although artificial intelligence is not the sole solution to problems between city government and stakeholders, it is one of the strong tools to increase the efficiency of city government for policy and decision-making by involving stakeholders through social innovation. Implementation of artificial intelligence in social innovation may also indicate how the city government can provide stimulus to other evolving digital devices for decision-making [58]. Several researchers emphasized the influence of artificial intelligence on social innovation [59], the impact of social innovation on smart decision-making [28], and the overall impact of artificial intelligence on smart decision-making [4], structural equation modeling of mediation, and moderation with contextual factors. Further, as [60] argued in their study, some direct relationships depend on contextual factors, so we tried to investigate the mediation impact of contextual variables: social innovation between independent and dependent variables. Believing the previous theories and research, we can develop our hypothesis as follows:

Hypothesis 2. Artificial intelligence contributes to social innovation positively in smart cities.

Hypothesis 3. Social innovation contributes to smart decision-making positively in smart cities.

Hypothesis 4. Artificial intelligence, using big data, has a positive influence on smart decisionmaking in smart cities mediated by social innovation.

\section{Research Methodology}

The primary goal of this research is to create a framework for a comprehensive understanding of the interaction between artificial intelligence and smart decision-making, with social innovation acting as a moderator. Longitudinal research is carried out to evaluate the hypothesis produced in this study and assess the test outcomes. It consists of investigations of community perceptions of the role of AI in decision-making. Primary data for this study were gathered. A total of 416 participants completed and returned survey questionnaires provided to them by emails, mail posts, and online, allowing us to improve the construct reliability and validity [61]. 


\subsection{Sample and Data Collection}

The study sample encompasses two different economies in Asia, namely Pakistan and South Korea. The main reason to select these two countries to collect data samples is to conduct a comparative analysis because South Korea is a developed country with a higher implementation of AI in decision-making [62]. However, Pakistan is relatively less developed and striving to achieve its targets to implement AI in all cities for decision-making.

The questionnaire for this study was grounded on relevant previous literature. We employed literature research and subject matter experts in social innovation to construct the scale instrument's content validity [63]. Because the questionnaire was created in Urdu and English and a Korean version was given, back-translation from English to Korean and then from Korean to English, and from English to Urdu and then Urdu to English, was performed to ensure the content's correctness. The Korean and Urdu versions were evaluated to see if the assertions were clear and intelligible, and it was examined again by specialists after the material was amended. The amended Korean and Urdu versions were then used to pre-test the 20 participants from Pakistan and Korea before sending the surveys to a mass population.

Participants were asked to complete a survey questionnaire on their opinions on the use of artificial intelligence in smart cities, social innovation, and smart decision-making by local governments. The survey questionnaire, which included questions regarding the trustworthiness of AI, the impact of AI on society, public confidence in AI, unemployment caused by AI, and the usage of AI for public service, was developed after evaluating prior research and was adapted from it $[64,65]$. Social innovation questions, in the second segment, concerning social entrepreneurship, social economy, local, and regional development, and design thinking were adapted from prior research [66,67]. Finally, the construct smart decision-making was measured by using five components such as use of new technologies for decision-making, data collection through sensors, optimistic solution for difficult situations, optimal and timely decision-making, and use of all available alternatives for smart decision-making [68].

A cross-sectional questionnaire survey was published online on social media in different groups and sent through emails in September 2021. The target audience for our survey was the Pakistani and the South Korean populations aged between 20 and 65 years, and they were requested to fill the survey questionnaire and send them back to us through email. Four hundred thirty-seven completed and usable questionnaire responses were eventually collected, with 52\% (227) from South Korea and 48\% (210) from Pakistan. A t-test was employed to detect any prejudice between early and late replies, but no significant variation was identified between the two sets of observations. Different demographic individualities by country of the data sample are shown in Table 1 below. We did not find any missing values from any of the participant's survey answers.

The sample data collected through the surveys were then analyzed utilizing the statistical program SPSS version 21. We used analytical methods such as correlation, factor analysis, multiple regression, and path analysis. The aspects of artificial intelligence, social innovation, and smart decision-making were identified using an exploratory factor analysis technique that was previously used by numerous scholars [69]. For path analysis, ordinary least squares regression allows a dependent variable in one equation to become an independent variable in another. As a result, it was utilized to explore the relationship between social innovation and smart decision-making using a variety of metrics. Path coefficients may also deconstruct associations between dependent and independent constructs into direct and indirect impacts to identify mediating influences. Teeratansirikool [69] used this method to test the mediating role of competitive strategy on the association between a firm's cost leadership and firm performance.

Several previous scholars have focused on comparative analysis studies between developed and developing countries on different topics; for example, [70] aimed to compare payments for environmental services, [71] intended to study the contribution of SMEs in economic development, [71] compared impact of capital flows and the stock market on 
countries' economic growth, and [72] conducted a comparative analysis of price instability on demand of oil in developed and developing countries. Most previous studies about the comparative analysis between developed and developing countries were based on existing real-time data [73]. However, the reason to use South Korea and Pakistan in our study is that no previous studies analyzed the public's perception to examine the impact of AI on decision-making in developed and developing countries simultaneously. The main reason for using two countries in our study is that Korea is a developed country where public managers implement AI-based decision-making policies, but Pakistan is a developing country where implementation of AI is partial or low in the decision-making process. Hence, this study tried to analyze the public's perception in these countries.

Table 1. Demographic characteristics of survey participants.

\begin{tabular}{|c|c|c|}
\hline Group & $\mathbf{N}$ & $\%$ \\
\hline \multicolumn{3}{|l|}{ Countries } \\
\hline Korea & 210 & 48 \\
\hline Pakistan & 227 & 52 \\
\hline Total & 437 & 100 \\
\hline \multicolumn{3}{|l|}{ Gender } \\
\hline Korea Male & 128 & 29 \\
\hline Korea Female & 82 & 19 \\
\hline Pakistan Male & 157 & 36 \\
\hline Pakistan Female & 70 & 16 \\
\hline Total & 437 & 100 \\
\hline \multicolumn{3}{|l|}{ Age } \\
\hline $20-35$ & 160 & 37 \\
\hline $36-50$ & 198 & 45 \\
\hline $51-65$ & 79 & 18 \\
\hline \multicolumn{3}{|l|}{ Education } \\
\hline High School & 47 & 11 \\
\hline University & 252 & 58 \\
\hline Master's Degree & 120 & 27 \\
\hline Ph.D. & 18 & 04 \\
\hline
\end{tabular}

\subsection{Measures}

To estimate the construct of this study, we collected data using three types of survey questionnaires. The survey form was uploaded in different groups on social media and sent to people from different walks of life by mail and emails to collect as many responses as possible. Participants were asked to complete questionnaires regarding their perceptions of artificial intelligence, social innovation, and their overall influence on smart decision-making. Participants' gender, age, and education were used as control variables in demographic characteristics. We received 465 responses to our survey, but 28 of them had missing values, so we eliminated them from our data, leaving 437 to study our constructions. Artificial intelligence was a predicted variable in our study framework, decision-making was an outcome variable, and social innovation was a mediator. Participants' survey responses were analyzed using a five-point Likert scale ranging from 1 to 5 , with 1 being "strongly disagree" and 5 being "strongly agree". The survey questionnaire scored artificial intelligence by three substances, social innovation by four, and smart decision-making by four objects.

We started our survey questionnaire with five questions for each variable, but we found some questions irrelevant while conducting factor analysis, so we removed 2 questions from AI and 1 question from social innovation and SDM variables. Using 3 or 4 items to investigate a variable is consistent with several previous studies where scholars used similar components to examine their variables. For instance, [68] used 4 items to investigate competitive strategy; [74] utilized 3 items for entrepreneurial education, 3 items for entrepreneurial self-efficiency, 4 items for entrepreneurial attitude, and 4 items for an entrepreneurial mindset to observe these variables; and [75] used 3 elements for or- 
ganizational commitment and 4 components for organizational culture to examine these constructs. A questionnaire to measure the components is given in Appendix A.

\subsection{Data Analysis}

For this study, SPSS software was utilized to evaluate the collected sample, and a multiple regression and bootstrap approach was performed to examine our hypothesis. In recent years, social science research has indicated a strong dependence on the bootstrap approach as one of the best traditional approaches for investigating mediating factors in social scientific domains [76]. Further, multiple regression using SPSS is regarded as one of the best novel alternatives to previous traditional analysis tools due to numerous recent improvements such as confirmatory analysis, non-linear impacts, and mediating and moderating impacts [77]. Numerous previous scholars proposed multiple regression statistical methods to examine the mediation effects using primary and secondary data $[78,79]$. Although several researchers used structural equational modelling (SEM) to investigate interaction mediation effects between independent and dependent variables [80,81], we assumed that multiple regression using SPSS is the best method for this study to explore our findings following [81] probed mediation effect of information on decision-making.

Confirmatory factor analysis (CFA) was conducted to create a measurement model of entire self-rating scales by a convergent validity test. The modification index is then used to select objects in the variables. The component with the greatest modification index value was removed first, and so on until the desired goodness of fits was achieved. Most goodness of fit indicators exceeded the cut-off threshold specified, but a few factor loadings were below the minimum required level of 0.5 . Hence, we removed them to obtain valid data for our framework. It is confirmed that factor loadings of all components of observed variables are greater than the critical point of 0.5 [82]. The absolute model fit index was discovered using the goodness-of-fit test, which assessed whether the data sample matches an overall framework's connecting path map.

We now reach the critical decision of whether the measurement model that we have described is valid after it has been defined and after it has passed all the essential reliability and validity tests. This was accomplished by determining the appropriate standard of goodness-of-fit for the model fit. The goodness of fit is the ability to determine how well the model fits into the dataset's variance-covariance structure. Based on evaluation criteria for quantitative measurements, the CFA measurement and structural model fit the data well. Cronbach's alpha coefficients were used to evaluate the measurements' reliability, and construct correlation was used to assess the validity of the sample. Previous research was used to construct the items for each variable. These indexes can provide superior evidence about construct reliability and validity. The acceptance level of Cronbach's alpha should be above the threshold of 0.50 .

Figure 1 demonstrates our research model where artificial intelligence depicts independence, dependence on smart decision-making, and social innovation as mediating variables. Our research model indicates a direct effect of artificial intelligence on smart decision-making, but with the inclusion of social innovation in the first model, the direct linear relationship turned to a mediating relationship. Three basic techniques are used for statistical mediation analysis: (1) causal stages, (2) coefficient difference, and (3) coefficient product [83]. All these strategies rely on data from the three regression equations listed below, following the examples by [84]:

$$
\begin{gathered}
\mathrm{SDM}=\beta_{10}+\beta_{11} \mathrm{AI}+\beta_{12} \text { CONTROLS }+\epsilon_{1} \\
\mathrm{SI}=\beta_{20}+\beta_{21} \mathrm{AI}+\beta_{22} \text { CONTROLS }+\epsilon_{2} \\
\mathrm{SDM}=\beta_{30}+\beta_{31} \mathrm{AI}+\beta_{32} \mathrm{SI}+\beta_{33} \text { CONTROLS }+\epsilon_{3}
\end{gathered}
$$

where $\beta_{10}, B_{20}$, and $\beta_{30}$ are intercepts, SDM indicates the dependent variable, AI describes the independent variable, SI is the mediator, $\beta_{11}, \beta_{21}$, and $\beta_{31}$ are the coefficients relating the independent variable and the dependent variable, $\beta_{32}$ is the coefficient concerning 
the mediator to the dependent variable attuned for the independent variable, and $\epsilon_{1}, \in_{2}$, and $\epsilon_{3}$ represent error terms in variables. $B_{12}, \beta_{22}$, and $\beta_{32}$ with CONTROLS designate to control gender, age, education, and nationality variables.

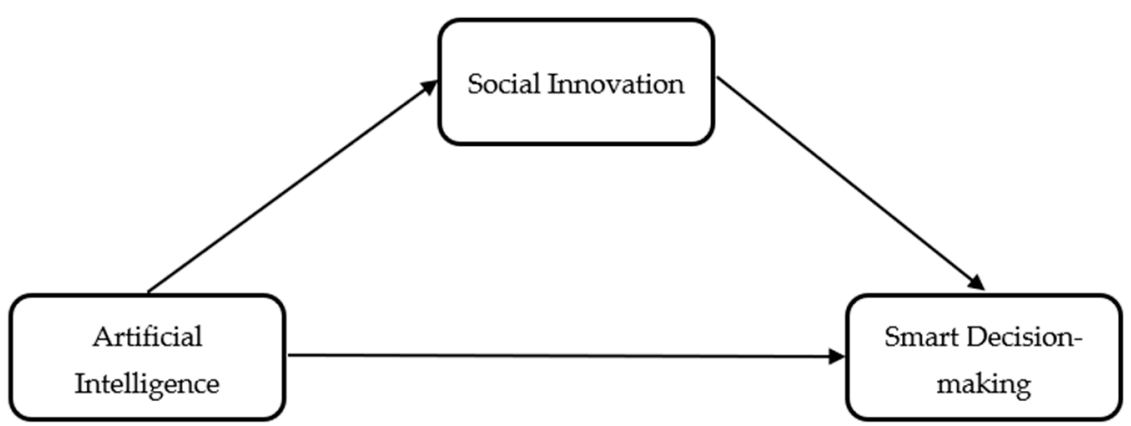

Figure 1. Mediating role of social innovation between AI on SDM in smart cities.

\section{Results}

Table 2 describes the outcomes of KMO for all three variables (AI as independent, SI as mediating, and SDM as dependent variable) is 0.531 , which is greater than 0.001 . This suggests that the data sample size utilized for this research was adequate. Further, the Chi-square result is 777.933 with a substantial significant level of 0.000 , which is again satisfactory.

Table 2. Bartlett Sphericity Test and KMO of Self Rating Items.

\begin{tabular}{|c|c|c|c|c|c|c|}
\hline \multirow{2}{*}{ Factors } & \multirow{2}{*}{ No of Items } & \multirow{2}{*}{ Component } & \multirow{2}{*}{$\mathbf{N}$} & \multirow{2}{*}{ KMO } & \multicolumn{2}{|c|}{ Bartlett Test } \\
\hline & & & & & Chi-Square & Sig \\
\hline Artificial Intelligence & 3 & 0.960 & 437 & & & \\
\hline Social Innovation & 4 & 0.786 & 437 & 0.531 & 777.933 & 0.000 \\
\hline Smart Decision-Making & 4 & 0.861 & 437 & & & \\
\hline
\end{tabular}

As explained in Table 3 below, the reliability analysis for 11 items were used to determine artificial intelligence's influence as an independent variable, smart decision-making as a dependent variable, and social innovation as a mediator factor. The 11 questions given below were dispersed as follows: 3 items were allocated to artificial intelligence, 4 objects were assigned to social innovation, and 4 to smart decision-making. We utilized reliability analysis to discover the reliability for each factor. The outcomes revealed that overall, Cronbach's Alpha was 0.914 of a total of 11 items with a sample size of 437, which indicated that all questions used to measure all the three factors were reliable for this study. Moreover, factor loadings for each component were greater than 0.7, except that of one A2, which was found to be 0.584 . However, several previous studies accepted factors with a value higher than 0.5 , so we added it as a reliable component. Factor loading for each component greater than 0.5 means that all questions asked from participants and used to measure factors were reliable and valid for this research. Table 2 describes the outcomes of $\mathrm{KMO}$ for all three variables (AI as independent, SI as mediating, and SDM as dependent variable) is 0.531 , which is greater than 0.001 . It suggests that the data sample size utilized for this research was adequate. Further, the Chi-square result is 777.933 with a substantial significant level of 0.000 , which is again satisfactory. 
Table 3. Construct Reliability and Validity.

\begin{tabular}{|c|c|c|c|}
\hline Cronbach's Alpha & Cronbach's Alpha Based on & d Items & $\mathrm{N}$ of Items \\
\hline \multirow[t]{3}{*}{0.914} & \multirow{2}{*}{\multicolumn{2}{|c|}{ Component }} & 11 \\
\hline & & & \\
\hline & 1 & 2 & 3 \\
\hline AI1 & 0.945 & & \\
\hline $\mathrm{AI} 2$ & 0.584 & & \\
\hline $\mathrm{AI} 3$ & 0.812 & & \\
\hline SI1 & & 0.771 & \\
\hline SI2 & & 0.701 & \\
\hline SI3 & & 0.724 & \\
\hline SI4 & & 0.754 & \\
\hline SDM1 & & & 0.833 \\
\hline SDM2 & & & 0.857 \\
\hline SDM3 & & & 0.850 \\
\hline SDM4 & & & 0.860 \\
\hline
\end{tabular}

Table 4 explains the correlation among different variables, data reliability, and descriptive statistics. The value of the mean for artificial intelligence was $3.855(\mathrm{SD}=0.804)$, indicating that respondents showed that they agreed to respond to the usage of $\mathrm{AI}$ in smart cities for decision-making and for social innovation $3.872(\mathrm{SD}=0.754)$, showing that most respondents believed in social innovation for decision-making using big data, and for smart decision-making, the value was $1.266(\mathrm{SD}=3.302)$, indicating that respondents were agreed strongly with smart decision-making in smart cities with SI and AI. The correlation between artificial intelligence and smart decision-making was $\left(r=0.811^{* *} ; p<0.01\right)$, which showed a significant positive relationship between both variables.

Table 4. Descriptive statistics, correlation coefficients, and reliability coefficients for variables.

\begin{tabular}{|c|c|c|c|c|c|c|c|c|}
\hline Variable & Mean & SD & AI & SI & SDM & GEN & AGE & EDU \\
\hline AI & 3.855 & 0.804 & 0.794 & & & & & \\
\hline SI & 3.872 & 0.754 & $0.679^{* *}$ & 0.812 & & & & \\
\hline SDM & 3.302 & 1.266 & $0.811^{* *}$ & $0.414^{* *}$ & 0.931 & & & \\
\hline GEN & 0.61 & 0.488 & $-0.487^{* *}$ & $-0.165^{* *}$ & $-0.480^{* *}$ & 1 & & \\
\hline AGE & 1.84 & 0.693 & 0.088 & $0.331^{* *}$ & -0.067 & $0.303^{* *}$ & 1 & \\
\hline EDU & 2.71 & 0.863 & -0.083 & -0.034 & $-0.103 *$ & 0.101 * & 0.050 & 1 \\
\hline
\end{tabular}

Notes: ${ }^{*}, *$ Correlation is significant at $0.05,0.01$ level (2-tailed), and Cronbach's alpha to test reliability is given on the diagonal line.

The correlation of artificial intelligence with social innovation was $(0.679 * * ; p<0.01)$, which revealed a similarly positive and significant relationship between AI and SI as assumed in the second hypothesis. Further, correlation $\left(\mathrm{r}=0.414^{* *} ; p<0.01\right)$ between social innovation and smart decision-making indicated a positive and significant relationship between independent and dependent variables, as anticipated in the third hypothesis. The Sobel test was conducted to test the mediating role of social innovation between the relationship of artificial intelligence and smart decision-making. Results from the Sobel Test given below explained a mediation association between independent and dependent variables.

Table 5 reveals a hierarchal multiple regression analysis to examine our research hypothesis, which stated that social innovation mediates artificial intelligence and smart decision-making. Regarding model 1, referring to the direct relationship between artificial intelligence and smart decision-making, the value of $\mathrm{B}=1.276$, and the value of Beta $=0.811$ with $p$-value $=0.000$, which implies a substantial and positive relationship between artificial intelligence and smart decision-making, supporting our first hypothesis. As for model 2, 
which applied multiple regression analysis to discover both artificial intelligence as an independent variable and social innovation as a mediator variable with smart decisionmaking as a dependent variable, the outcomes revealed that the value of $\mathrm{B}=1.545$, and the value of Beta $=0.981$ with $p$-value 0.000 , as an indirect relationship between artificial intelligence and smart decision-making; on the other hand, the value of $B=0.422$, and the value of Beta $=0.252$ with $p$-value 0.000 as mediation between social innovation and smart decision-making. The findings established a positive and substantial direct and indirect association between artificial intelligence and smart decision-making. Moreover, social innovation has a strong positive and significant mediating impact between artificial intelligence and smart decision-making; hence, hypotheses 2, 3, and 4 are significantly supported empirically.

Table 5. Hierarchical multiple regression, Artificial Intelligence, Social Innovation, and Smart Decision-Making.

\begin{tabular}{|c|c|c|c|c|c|c|}
\hline \multicolumn{7}{|c|}{ Coefficients $^{a}$} \\
\hline \multirow{2}{*}{\multicolumn{2}{|c|}{ Model }} & \multicolumn{2}{|c|}{ Unstandardized Coefficients } & \multirow{2}{*}{$\begin{array}{c}\text { Standardized Coefficients } \\
\text { Beta }\end{array}$} & \multirow{2}{*}{$\mathbf{t}$} & \multirow{2}{*}{ Sig. } \\
\hline & & B & Std. Error & & & \\
\hline \multirow{2}{*}{1} & (Constant) & 1.619 & 0.174 & & 9.298 & 0.000 \\
\hline & $\mathrm{AI}$ & 1.276 & 0.044 & 0.811 & 28.861 & 0.000 \\
\hline \multirow{3}{*}{2} & (Constant) & 1.021 & 0.187 & & 5.470 & 0.000 \\
\hline & $\mathrm{AI}$ & 1.545 & 0.057 & 0.981 & 27.018 & 0.000 \\
\hline & SI & 0.422 & 0.061 & 0.252 & 6.929 & 0.000 \\
\hline
\end{tabular}

Table 6 demonstrates the outcomes of the Sobel test to analyze the mediation analysis. The results reveal the direct association between artificial intelligence and smart decisionmaking, $p$-value $=0.000$. It suggested that there is a considerable and positive direct correlation between artificial intelligence and smart decision-making. Furthermore, $p$ value is 0.000 as an indirect association between artificial intelligence and smart decisionmaking. Moreover, the results proved a significant and progressive direct and indirect affiliation between artificial intelligence and smart decision-making; social innovation has a substantial positive and significant mediating role between artificial intelligence and smart decision-making.

Table 6. Sobel Test.

\begin{tabular}{cccccc}
\hline & Input & Test & Test Statistic: & Std. Error: & $p$-Value: \\
\hline $\mathrm{a}$ & 1.545 & Sobel test: & 6.70315028 & 0.09726621 & 0.000 \\
\hline $\mathrm{b}$ & 0.422 & Aroian test: & 6.69887152 & 0.09732833 & 0.000 \\
\hline $\mathrm{S}_{\mathrm{a}}$ & 0.057 & Goodman test: & 6.70743726 & 0.09720404 & 0.000 \\
\hline $\mathrm{S}_{\mathrm{b}}$ & 0.061 & & & & \\
\hline
\end{tabular}

\section{Discussions and Implications}

\subsection{Discussions}

Because of sophisticated algorithms, big data, and greater storage and processing capacity, AI systems are augmented with integrated components of digital systems, dramatically influencing decision-making. As a result, there is a growing demand for researchers of IT system social science to comprehend and analyze the impact of artificial intelligence on decision-making and contribute to the practical success and theoretical advancement of AI applications [4]. Furthermore, we must identify and examine the indirect elements that might influence the good or negative relationship between AI and decision-making. This 
study aims to meet this need by recognizing, evaluating, and researching an important component in this research field, namely social innovation. Several earlier researchers discovered a moderating effect of elements between AI and decision-making [85] and the mediating influence of elements between two constructs [86,87]. We implied social innovation as mediating factor to investigate the relationship between artificial intelligence and smart decision-making.

This study looked specifically at social innovation as a mediating element that might influence big data's smart decision-making process. The findings demonstrated a significant mediating role of social innovation between AI and SDM. First, we looked at the direct association between AI and SDM, which was signed between both variables. Then, we incorporated social innovation as a moderating variable between independent and independent variables. An analysis of the direct and indirect interactions between AI, SI, and SDM revealed a substantial direct relationship between AI and SDM and an entire mediating influence of SI between AI and SDM. Smart city managers can gather, convert, and transport data using surveillance cameras, environmental sensors, electronic billboards, traffic management systems, charging stations, Wi-Fi, and other devices. While there is a high degree of AI use in the city, there is a greater possibility that the city's governance will be better and that choices for the public will be made wisely.

This research aims to determine if social innovation has a mediating effect between external construct AI and endogenous construct SDM. We demonstrated this link with empirical evidence that it exists and is highly supported when studied. The first hypothesis predicted a substantial relationship between artificial intelligence and smart decisionmaking, which was established correctly, and we discovered significant outcomes. We employed SPSS software and regression analysis to establish the strength and significance of these relationships, which were substantially and significantly positive. Local governments in cities employ gadgets and devices connected to the internet. They are influenced by the usage of big data acquired through sensors and other artificial intelligence sources, which is a good sign.

Further, the second hypothesis predicted a direct influence of artificial intelligence on social innovation. The third hypothesis implicated a direct positive relationship between social innovation and smart decision-making. We proved this with an empirical investigation; hence, we conclude that such relationships exist between independent and dependent variables. Finally, we determined with our experimental testimony that social innovation has a strong, substantial mediating impact between AI and SDM, as we anticipated in our fourth hypothesis.

\subsection{Implications}

The findings of this study have ramifications for local city managers and smart city governors. Because our research was done in the public and private sectors in Pakistan and South Korea, city managers and governors may benefit from it in various ways. Small or rural communities may not benefit from this study due to a lack of resources, technology, social inclusion, political power, and other variables, but larger cities in these nations may benefit. The major goal of this study is smart decision-making; thus, we have emphasized the aspects that contribute positively and substantially so that local government managers should keep these factors in mind when developing public policies and choices. Sensors are becoming essential types of data collecting equipment that may be utilized for decisionmaking in smart cities for improved governance. Furthermore, local government can share such collected data with entrepreneurs, businesses, and industries, as well as for the prosperity of the society, and all relevant stakeholders, including such social innovators, should be involved in the decision-making process by local government, bearing in mind that such decisions will affect them directly or indirectly.

Because of various limitations, the findings and comments in this research should be interpreted with vigilance. Our first potential drawback is the very small sample size of 437 survey questions. Although there have been multiple earlier studies with smaller 
sample sizes than ours, we feel that the outcomes may be different with a larger sample size. Next, while we worked hard to avoid any social or nationalist pressures on the participants, it is conceivable that some of the contenders sensed some implied communal or patriotism, which required them to respond to the questions in favor of their country because people of many nationalities wants to demonstrate their nation as being better. Lastly, this survey was done in both developed and emerging economies, and most respondents were educated and earned a middle-income. There is a chance that the results will change if the sample is drawn from various economies or drawn from a population with a low level of education and income.

\section{Conclusions and Future Research}

Artificial intelligence has proven to be beneficial in a variety of industries. As AI has grown in popularity because of big data, enhanced algorithms, and increased processing power and storage, AI systems are becoming an integrated component of digital systems and significantly influence smart decision-making. Consequently, there is a growing need for social science and information systems researchers to examine and comprehend the ramifications for decision-making and contribute to AI technologies' academic growth and empirical success. This work intends to meet this requirement by analyzing and emphasizing the curative function of social innovation in the relationship of AI and smart decision-making, emphasizing the significant issues and opportunities for future studies. Four research hypotheses are presented, focused on the usage and influence of AI for decision-making, with social innovation acting as a mediator. Our multiple regression results using SPSS suggest that AI using big data generated from sensors significantly influences social innovation and smart decision-making in smart cities. Furthermore, it is statistically proven that social innovation plays a substantial and important mediating role in the interaction between AI and smart decision-making.

Although the hypotheses given in this study are primarily for study in AI for decisionmaking and social innovation mediation, they can also offer valuable recommendations for research on the application and effect of $\mathrm{AI}$ in general, the impact of $\mathrm{AI}$ on decision-making on different industries, and, most importantly, the analysis of these significant relationships in different contexts using interaction variables to achieve interesting outcomes.

Author Contributions: S.A.A.B.; conceptualization, methodology, validation, Formal Analysis, investigation, Writing-Original draft preparation, S.M.; conceptualization, methodology, writing—review and editing, funding acquisition. All authors have read and agreed to the published version of the manuscript.

Funding: This research was supported by Inha University (66287-01).

Institutional Review Board Statement: Not applicable.

Informed Consent Statement: Not applicable.

Data Availability Statement: No new data were created in this study. Data sharing is not applicable to this research.

Conflicts of Interest: The authors declare no conflict of interest.

\section{Appendix A}

Questionnaire Items

\section{Artificial Intelligence}

- In my opinion, Information from artificial intelligence science community is trustworthy;

- In my opinion, artificial intelligence science community has much influence on society;

- I have very much confidence in the artificial intelligence science community;

- In my opinion, artificial intelligence is contributing to unemployment in my country;

- In my opinion, government should utilize artificial intelligence for public services. 


\section{Social Innovation}

- In my opinion, social entrepreneurship works for betterment of the community and not to make profits;

- In my opinion, social Economy has primacy of the individuals and the social objective over capital;

- In my opinion, local and regional development helps to raise living standard of the people in urban area;

- In my opinion, design thinking guides the decision/policy makers to plan the city better.

\section{Smart Decision-making}

- In my opinion, local government uses new technologies rather than using old methods for decision-making;

- In my opinion, local government gathers lot of data on any opportunity that arises to decide better for public;

- In my opinion, whenever local government face a difficult situation, its optimistic about finding a good solution for public;

- In my opinion, my local government doesn't delay decision-making for public whenever it needed before it's too late;

- In my opinion, local government considers all the available alternatives for decision-making.

\section{References}

1. Allam, Z; Dhunny, Z.A. On big data, artificial intelligence and smart cities. Cities 2019, 89, 80-91. [CrossRef]

2. Batty, M. Artificial Intelligence and Smart Cities; SAGE Publications Sage: London, UK, 2018.

3. Collins, C.; Dennehy, D.; Conboy, K.; Mikalef, P. Artificial intelligence in information systems research: A systematic literature review and research agenda. Int. J. Inf. Manag. 2021, 60, 102383. [CrossRef]

4. Duan, Y.; Edwards, J.S.; Dwivedi, Y.K. Artificial intelligence for decision making in the era of Big Data-evolution, challenges and research agenda. Int. J. Inf. Manag. 2019, 48, 63-71. [CrossRef]

5. Mikalef, P.; Lemmer, K.; Schaefer, C.; Ylinen, M.; Fjørtoft, S.O.; Torvatn, H.Y.; Gupta, M.; Niehaves, B. Enabling AI capabilities in government agencies: A study of determinants for European municipalities. Gov. Inf. Q. 2021, 101596. [CrossRef]

6. Myeong, S.; Jung, Y.; Lee, E. A study on determinant factors in smart city development: An analytic hierarchy process analysis. Sustainability 2018, 10, 2606. [CrossRef]

7. Alam, J.R.; Sajid, A.; Talib, R.; Niaz, M. A review on the role of big data in business. Int. J. Comput. Sci. Mob. Comput. 2014, 3, 446-453.

8. Russell, S.; Norvig, P. Artificial Intelligence: A Modern Approach; Prentice Hall: Hoboken, NJ, USA, 2002.

9. Zanella, A.; Bui, N.; Castellani, A.; Vangelista, L.; Zorzi, M. Internet of things for smart cities. IEEE Internet Things J. 2014, 1, $22-32$. [CrossRef]

10. Pomerol, J.-C. Artificial intelligence and human decision making. Eur. J. Oper. Res. 1997, 99, 3-25. [CrossRef]

11. Raisch, S.; Krakowski, S. Artificial intelligence and management: The automation-augmentation paradox. Acad. Manag. Rev. 2021, 46, 192-210. [CrossRef]

12. Berntzen, L.; Johannessen, M.R.; El-Gazzar, R. Smart Cities, Big Data and Smart Decision-making-Understanding "Big Data" in Smart City Applications. In Proceedings of the ICDS 2018, The Twelfth International Conference on Digital Society and eGovernments, Rome, Italy, 25-29 March 2018.

13. Vesco, A. Handbook of Research on Social, Economic, and Environmental Sustainability in the Development of Smart Cities; IGI Global: Hershey, PA, USA, 2015.

14. Atlam, H.F.; Walters, R.J.; Wills, G.B. Fog computing and the internet of things: A review. Big Data Cogn. Comput. 2018, 2, 10. [CrossRef]

15. Albino, V.; Berardi, U.; Dangelico, R.M. Smart cities: Definitions, dimensions, performance, and initiatives. J. Urban Technol. 2015, 22, 3-21. [CrossRef]

16. Harrison, C.; Eckman, B.; Hamilton, R.; Hartswick, P.; Kalagnanam, J.; Paraszczak, J.; Williams, P. Foundations for smarter cities. IBM J. Res. Dev. 2010, 54, 1-16. [CrossRef]

17. Ahad, M.A.; Paiva, S.; Tripathi, G.; Feroz, N. Enabling technologies and sustainable smart cities. Sustain. Cities Soc. 2020, 61, 102301. [CrossRef]

18. Ben Rjab, A.; Mellouli, S. Artificial Intelligence in Smart Cities: Systematic Literature Network Analysis. In Proceedings of the 12th International Conference on Theory and Practice of Electronic Governance, Melbourne, Australia, 3-5 April 2019.

19. Thakker, D.; Mishra, B.K.; Abdullatif, A.; Mazumdar, S.; Simpson, S. Explainable Artificial Intelligence for Developing Smart Cities Solutions. Smart Cities 2020, 3, 65. [CrossRef]

20. Voda, A.I.; Radu, L.D. Artificial intelligence and the future of smart cities. Broad Res. Artif. Intell. Neurosci. 2018, 9, 110-127. 
21. Lopes, N.V. Smart governance: A key factor for smart cities implementation. In Proceedings of the 2017 IEEE International Conference on Smart Grid and Smart Cities (ICSGSC), Singapore, 23-26 July 2017.

22. Vrabie, C.; Tirziu, A. E-Participation-A Key Factor in Developing Smart Cities. Available online: https://ideas.repec.org/p/pra/ mprapa/77707.html (accessed on 13 October 2021).

23. Deakin, M.; Al Waer, H. From intelligent to smart cities. Intell. Build. Int. 2011, 3, 140-152. [CrossRef]

24. Diakaki, C.; Grigoroudis, E.; Kabelis, N.; Kolokotsa, D.; Kalaitzakis, K.; Stavrakakis, G. A multi-objective decision model for the improvement of energy efficiency in buildings. Energy 2010, 35, 5483-5496. [CrossRef]

25. de Fine Licht, K.; de Fine Licht, J. Artificial intelligence, transparency, and public decision-making. AI Soc. 2020, 35, 917-926. [CrossRef]

26. Jarrahi, M.H. Artificial intelligence and the future of work: Human-AI symbiosis in organizational decision making. Bus. Horiz. 2018, 61, 577-586. [CrossRef]

27. Morrar, R.; Arman, H.; Mousa, S. The fourth industrial revolution (Industry 4.0): A social innovation perspective. Technol. Innov. Manag. Rev. 2017, 7, 12-20. [CrossRef]

28. Gibson-Graham, J.; Roelvink, G. Social innovation for community economies. In Social Innovation and Territorial Development; Routledge: Oxfordshire, UK, 2016; pp. 41-54.

29. Kankanhalli, A.; Charalabidis, Y.; Mellouli, S. IoT and AI for Smart Government: A Research Agenda; Elsevier: Amsterdam, The Netherlands, 2019

30. Scholl, H.J.; AlAwadhi, S. Creating Smart Governance: The key to radical ICT overhaul at the City of Munich. Inf. Polity 2016, 21, 21-42. [CrossRef]

31. Surya, L. Artificial Intelligence in Public Sector. Int. J. Innov. Eng. Res. Technol. 2019, 6, 2394-3696.

32. Young, M.M.; Bullock, J.B.; Lecy, J.D. Artificial discretion as a tool of governance: A framework for understanding the impact of artificial intelligence on public administration. Perspect. Public Manag. Gov. 2019, 2, 301-313. [CrossRef]

33. Meijer, A.; Thaens, M. Quantified street: Smart governance of urban safety. Inf. Polity 2018, 23, 29-41. [CrossRef]

34. Park, Y.J.; Choe, Y.J.; Park, O.; Park, S.Y.; Kim, Y.-M.; Kim, J.; Kweon, S.; Woo, Y.; Gwack, J.; Kim, S.S.; et al. Contact tracing during coronavirus disease outbreak, South Korea, 2020. Emerg. Infect. Dis. 2020, 26, 2465. [CrossRef] [PubMed]

35. Giffinger, R.; Kramar, H. Benchmarking, profiling and ranking of cities: The 'European Smart Cities' approach. In Place-Based Performance Metrics in Building Sustainable Cities; Routledge: Oxfordshire, UK, 2021.

36. Gil-Garcia, J.R.; Pardo, T.A.; Nam, T. What makes a city smart? Identifying core components and proposing an integrative and comprehensive conceptualization. Inf. Polity 2015, 20, 61-87. [CrossRef]

37. Phillips-Wren, G.; Jain, L. Artificial intelligence for decision making. In Proceedings of the International Conference on KnowledgeBased and Intelligent Information and Engineering Systems, Bournemouth, UK, 9-11 October 2006.

38. Kermany, D.S.; Goldbaum, M.; Cai, W.; Valentim, C.C.; Liang, H.; Baxter, S.L.; McKeown, A.; Yan, F.; Wu, X.; Yan, F.; et al Identifying medical diagnoses and treatable diseases by image-based deep learning. Cell 2018, 172, 1122-1131.e1129. [CrossRef]

39. Bennett, C.C.; Hauser, K. Artificial intelligence framework for simulating clinical decision-making: A Markov decision process approach. Artif. Intell. Med. 2013, 57, 9-19. [CrossRef]

40. McGovern, A.; Elmore, K.L.; Gagne, D.J.; Haupt, S.E.; Karstens, C.D.; Lagerquist, R.; Smith, T.; Williams, J.K. Using artificial intelligence to improve real-time decision-making for high-impact weather. Bull. Am. Meteorol. Soc. 2017, 98, 2073-2090. [CrossRef]

41. Hall, R.E.; Bowerman, B.; Braverman, J.; Taylor, J.; Todosow, H.; Von Wimmersperg, U. The Vision of a Smart City; Brookhaven National Lab.: Upton, NY, USA, 2000.

42. Arasteh, H.; Hosseinnezhad, V.; Loia, V.; Tommasetti, A.; Troisi, O.; Shafie-khah, M.; Siano, P. Iot-based smart cities: A survey. In Proceedings of the 2016 IEEE 16th International Conference on Environment and Electrical Engineering (EEEIC), Florence, Italy, 7-10 June 2016.

43. Cardullo, P.; Kitchin, R. Smart urbanism and smart citizenship: The neoliberal logic of 'citizen-focused'smart cities in Europe. Environ. Plan. C Politics Space 2019, 37, 813-830. [CrossRef]

44. Dameri, R.P. Searching for smart city definition: A comprehensive proposal. Int. J. Comput. Technol. 2013, 11, $2544-2551$. [CrossRef]

45. Gaur, A.; Scotney, B.; Parr, G.; McClean, S. Smart city architecture and its applications based on IoT. Procedia Comput. Sci. 2015, 52, 1089-1094. [CrossRef]

46. Caragliu, A.; Del Bo, C.; Nijkamp, P. Smart cities in Europe. J. Urban Technol. 2011, 18, 65-82. [CrossRef]

47. Batty, M.; Yeh, T. The Promise of Expert Systems for Urban Planning; Elsevier: Amsterdam, The Netherlands, 1991.

48. Alvarez, R. The relevance of informational infrastructures in future cities. Field Actions Sci. Rep. J. Field Actions 2017, 17, 12-15.

49. Conway, S. Interactive governance: Advancing the paradigm. Administration 2020, 68, 63-68. [CrossRef]

50. Torfing, J.; Peters, B.G.; Pierre, J.; Sørensen, E. Interactive Governance: Advancing the Paradigm; Oxford University Press: Oxford, UK, 2012.

51. Meijer, A.; Bolívar, M.P.R. Governing the smart city: A review of the literature on smart urban governance. Int. Rev. Adm. Sci. 2016, 82, 392-408. [CrossRef]

52. Kundu, D. Urban development programmes in India: A critique of JNNURM. Soc. Chang. 2014, 44, 615-632. [CrossRef]

53. Capra, C.F. The Smart City and its citizens: Governance and citizen participation in Amsterdam Smart City. Int. J. E-Plan. Res. (IJEPR) 2016, 5, 20-38. [CrossRef] 
54. Mora, L.; Bolici, R. How to become a smart city: Learning from Amsterdam. In Proceedings of the International conference on Smart and Sustainable Planning for Cities and Regions, Bolzano, Italy, 22-24 March 2015.

55. Capra, C.F. The smart city and its citizens: Governance and citizen participation in Amsterdam Smart City. In Smart Cities and Smart Spaces: Concepts, Methodologies, Tools, and Applications; IGI Global: Hershey, PA, USA, 2019; pp. 1407-1427.

56. Somayya, M.; Ramaswamy, R. Amsterdam Smart City (ASC): Fishing village to sustainable city. WIT Trans. Ecol. Environ. 2016, 204, 831-842.

57. Phills, J.A.; Deiglmeier, K.; Miller, D.T. Rediscovering social innovation. Stanf. Soc. Innov. Rev. 2008, 6, 34-43.

58. Mehr, H.; Ash, H.; Fellow, D. Artificial intelligence for citizen services and government. Ash Cent. Democr. Gov. Innov. Harv. Kennedy Sch. 2017, 1-12. Available online: https://ash.harvard.edu/files/ash/files/artificial_intelligence_for_citizen_services.pdf (accessed on 18 October 2021).

59. Dargham, M.; Hachimi, H. Artificial Intelligence \& the emergence of social innovation Case of the Group" Crédit Agricole" in Morocco. In Proceedings of the 2021 7th International Conference on Optimization and Applications (ICOA), Wolfenbüttel, Germany, 19-20 May 2021.

60. Little, T.D.; Card, N.A.; Bovaird, J.A.; Preacher, K.J.; Crandall, C.S. Structural equation modeling of mediation and moderation with contextual factors. Modeling Contextual Eff. Longitud. Stud. 2007, 1, 207-230.

61. Ma, S.-J.; Wang, W.-J.; Tang, M.; Chen, H.; Ding, F. Evaluation of the construct reliability and validity of the DSM-5 Self-Rated Level 1 Cross-Cutting Symptom Measure-Chinese version in maintenance hemodialysis patients. J. Int. Med. Res. 2021, 49, 3000605211012661. [CrossRef]

62. Kim, H.-S. Decision-making in artificial intelligence: Is it always correct? J. Korean Med. Sci. 2020, 35, e1. [CrossRef]

63. Osburg, T.; Schmidpeter, R. Social innovation. In Solutions for a Sustainable Future; Springer: Berlin/Heidelberg, Germany, 2013.

64. Müller, V.C.; Bostrom, N. Future progress in artificial intelligence: A survey of expert opinion. In Fundamental Issues of Artificial Intelligence; Springer: Berlin/Heidelberg, Germany, 2016; pp. 555-572.

65. Ongena, Y.P.; Haan, M.; Yakar, D.; Kwee, T.C. Patients' views on the implementation of artificial intelligence in radiology: Development and validation of a standardized questionnaire. Eur. Radiol. 2020, 30, 1033-1040. [CrossRef]

66. Kleverbeck, M.; Krlev, G.; Mildenberger, G.; Strambach, S.; Thurmann, J.-F.; Terstriep, J.; Wloka, L. Indicators for measuring social innovation. Atlas Soc. Innov. 2019, 2, 98-101.

67. Mulgan, G.; Joseph, K.; Norman, W. Indicators for social innovation. In Handbook of Innovation Indicators and Measurement; Edward Elgar Publishing: Cheltenham, UK, 2013.

68. Klug, H.; Kmoch, A. Operationalizing environmental indicators for real time multi-purpose decision making and action support. Ecol. Model. 2015, 295, 66-74. [CrossRef]

69. Teeratansirikool, L.; Siengthai, S.; Badir, Y.; Charoenngam, C. Competitive strategies and firm performance: The mediating role of performance measurement. Int. J. Product. Perform. Manag. 2013, 62, 168-184. [CrossRef]

70. Wunder, S.; Engel, S.; Pagiola, S. Taking stock: A comparative analysis of payments for environmental services programs in developed and developing countries. Ecol. Econ. 2008, 65, 834-852. [CrossRef]

71. Pandya, V.M. Comparative analysis of development of SMEs in developed and developing countries. In Proceedings of the 2012 International Conference on Business and Management, Tallinn, Estonia, 3-6 September 2012.

72. Jobling, A.; Jamasb, T. Price volatility and demand for oil: A comparative analysis of developed and developing countries. Econ. Anal. Policy 2017, 53, 96-113. [CrossRef]

73. Choong, C.-K.; Baharumshah, A.Z.; Yusop, Z.; Habibullah, M.S. Private capital flows, stock market and economic growth in developed and developing countries: A comparative analysis. Jpn. World Econ. 2010, 22, 107-117. [CrossRef]

74. Wardana, L.W.; Narmaditya, B.S.; Wibowo, A.; Mahendra, A.M.; Wibowo, N.A.; Harwida, G.; Rohman, A.N. The impact of entrepreneurship education and students' entrepreneurial mindset: The mediating role of attitude and self-efficacy. Heliyon $\mathbf{2 0 2 0}$ 6, e04922. [CrossRef] [PubMed]

75. Nikpour, A. The impact of organizational culture on organizational performance: The mediating role of employee's organizational commitment. Int. J. Organ. Leadersh. 2017, 6, 65-72. [CrossRef]

76. Albright, J.J.; Marinova, D.M. Estimating Multilevel Models Using SPSS, Stata, SAS and R; Indiana University: Bloomington, IN, USA, 2015.

77. Rosopa, P.J.; Stone-Romero, E.F. Problems with detecting assumed mediation using the hierarchical multiple regression strategy. Hum. Resour. Manag. Rev. 2008, 18, 294-310. [CrossRef]

78. Preacher, K.J.; Hayes, A.F. SPSS and SAS procedures for estimating indirect effects in simple mediation models. Behav. Res. Methods Instrum. Comput. 2004, 36, 717-731. [CrossRef] [PubMed]

79. Li, S.D. Testing mediation using multiple regression and structural equation modeling analyses in secondary data. Eval. Rev. 2011, 35, 240-268. [CrossRef]

80. Gunzler, D.; Chen, T.; Wu, P.; Zhang, H. Introduction to mediation analysis with structural equation modeling. Shanghai Arch. Psychiatry 2013, 25, 390.

81. Wan Omar, W.; Hussin, F. Transformational leadership style and job satisfaction relationship: A study of structural equation modeling (SEM). Int. J. Acad. Res. Bus. Soc. Sci. 2013, 3, 346-365.

82. Gill, S.; Khurshid, M.K.; Mahmood, S.; Ali, A. Factors effecting investment decision making behavior: The mediating role of information searches. Eur. Online J. Nat. Soc. Sci. 2018, 7, 758-767.

83. Hair, J.F. Multivariate Data Analysis; Springer: Berlin/Heidelberg, Germany, 2009. 
84. MacKinnon, D.P.; Krull, J.L.; Lockwood, C.M. Equivalence of the mediation, confounding and suppression effect. Prev. Sci. 2000, 1, 173-181. [CrossRef]

85. Howell, D.C. Statistical Methods for Psychology; Cengage Learning: Boston, MA, USA, 2012.

86. Chinchanachokchai, S.; Thontirawong, P.; Chinchanachokchai, P. A tale of two recommender systems: The moderating role of consumer expertise on artificial intelligence based product recommendations. J. Retail. Consum. Serv. 2021, 61, 102528. [CrossRef]

87. Panichayakorn, T.; Jermsittiparsert, K. Mobilizing Organizational Performance through Robotic and Artificial Intelligence Awareness in Mediating Role of Supply Chain Agility. Int. J. Supply Chain. Manag. 2019, 8, 757-768. 